\title{
Not-So-Routine Electron Probe Microanalyses of Jarosite
}

Heather Lowers*, George Desborough, Jane Hammarstrom, Gregg Swayze, Kathy Smith, and Sharon Diehl

*U.S. Geological Survey, MS 973, Denver, Colorado, 80225, USA

Jarosite, ideally $\mathrm{KFe}_{3}^{3+}\left(\mathrm{SO}_{4}\right)_{2}(\mathrm{OH})_{6}$, has received recent attention as a major generator of acid in mine waste piles on Earth [1] as well as evidence for the existence of water on Mars [2]. In addition to the analyses of naturally occuring jarosite, workers have synthesized jarosite to understand its chemical and physical properties, particularly the amount of $\mathrm{H}_{3} \mathrm{O}^{+}$and $\mathrm{Na}$ that may substitute for $\mathrm{K}$ and cation deficiencies in the Fe site. The interpretations of these experiments often rely on data obtained by electron probe microanalyses (EPMA). Often, the interpretations do not take into account the effects of jarosite-beam interactions. The properties of jarosite that make it a not-so-routine mineral to analyze include beam sensitivity, small particle size, and chemical heterogeneity; all of these properties complicate interpretation of EPMA data.

Jarosite-beam interactions result in alkali migration and specimen damage at various operating conditions. EPMA operating conditions of jarosite analyses in the literature range from 10-20 $\mathrm{kV}, 5-30 \mathrm{nA}$ (cup), and spot to $10 \mu \mathrm{m}$ beam diameter. Figure 1 shows the effects of various operating conditions at $15 \mathrm{kV}$ on $\mathrm{K}$ counts. The effects for $\mathrm{Na}$ loss are similar, but more pronounced. Reducing the accelerating voltage and beam diameter tend to minimize alkali loss. Using operating conditions of $10 \mathrm{kV}, 20 \mathrm{nA}$, and $5 \mu \mathrm{m}$ beam diameter, $\mathrm{Na}$ and $\mathrm{K}$ count rates remained relatively constant for the entire analysis time with no visible specimen damage.

Operating conditions of $10 \mathrm{kV}$ and $5 \mu \mathrm{m}$ beam diameter produce a $\sim 4 \mathrm{~m}^{3}$ excitation volume, whereas operating conditions of $15 \mathrm{kV}$ and $5 \mu \mathrm{m}$ beam diameter produce an $\sim 8 \mu^{3}$ excitation volume. Many synthetic jarosites reported in the literature are less than $5 \mu \mathrm{m}$ in diameter, whereas, naturally occurring jarosite can grow larger than $1 \mathrm{~mm}$. Analysis of jarosite smaller than the excitation volume results in low totals and incorrect cation ratios. Data collected under these circumstances must be used with caution when concluding that Fe deficiencies exist and/or $\mathrm{H}_{3} \mathrm{O}^{+}$has substituted for $\mathrm{K}$. In addition, it has been shown that deficiencies in the $\mathrm{K}$-monovalent site may not be due to the presence of $\mathrm{H}_{3} \mathrm{O}^{+}$, but rather to vacancies in the crystal structure [3].

Crystal chemistry of jarosite allows for multiple substitutions within the lattice. Backscattered electron images can reveal chemical zonation within grains. This information can be used to prevent analysis of overlapping chemical zones. However, orientation of chemical zones with depth is often not known; therefore, the beam may parallel or intersect the chemical zones at depth within the excitation volume (Figure 2). Jarosite may display chemical zoning on a scale smaller than the excitation volumes described above, in which case more than one zone will be analyzed at once (Figure 2). Interpretations regarding solid solution between endmembers (i.e. $\mathrm{K}, \mathrm{Na}$, or $\mathrm{H}_{3} \mathrm{O}^{+}$) must consider the possibilities of heterogeneities within the excitation volume. 
EPMA of jarosite is not routine and requires knowledge of specimen-beam interactions and crystal-chemical properties. If the above factors are not taken into consideration, this may lead to errors in data interpretation, perhaps on a planetary scale.

References

[1] G. Desborough et al. U.S. Geological Survey OFR 99-322 (1999).

[2] G. Klingelhofer et al. Science 306 (2004) 1740-1745.

[3] J. Majzlan et al. Phys Chem Minerals 31 (2004) 518-531.

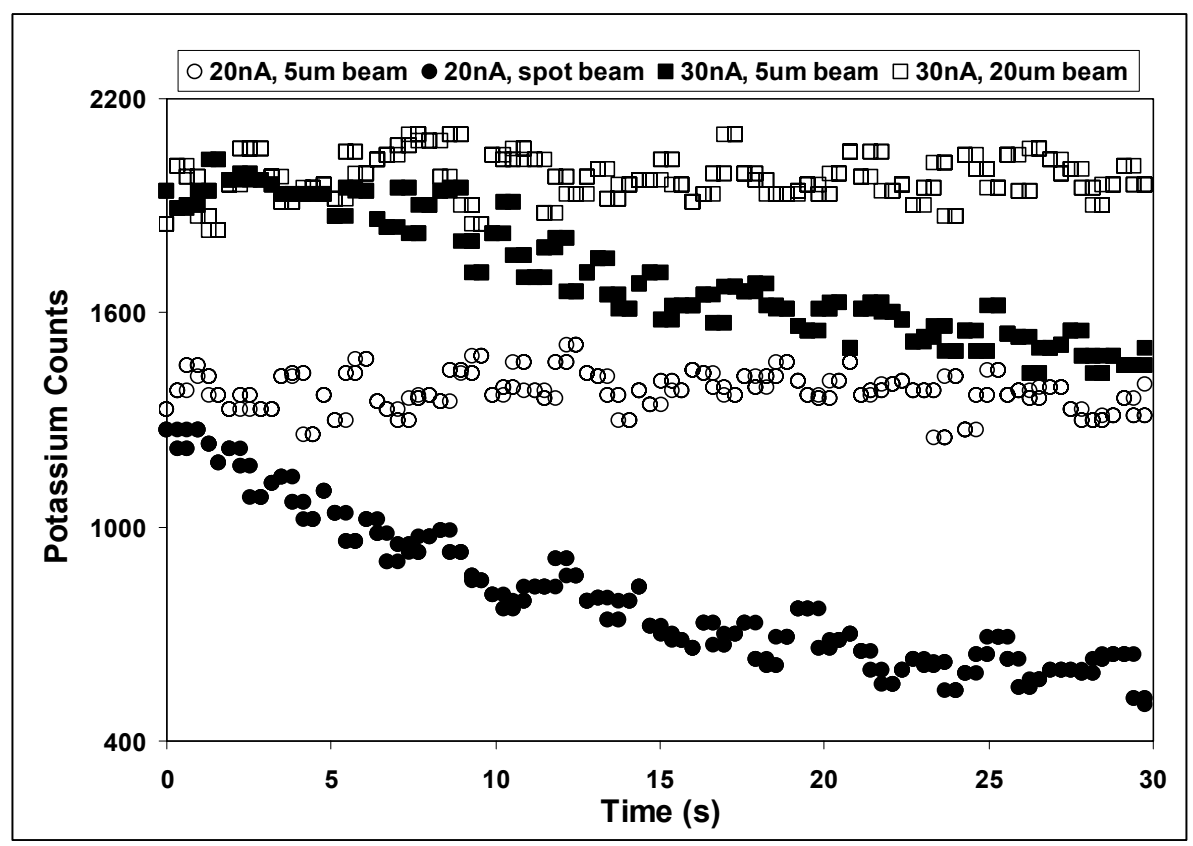

Figure 1. K-counts at various operating conditions $(15 \mathrm{kV})$.
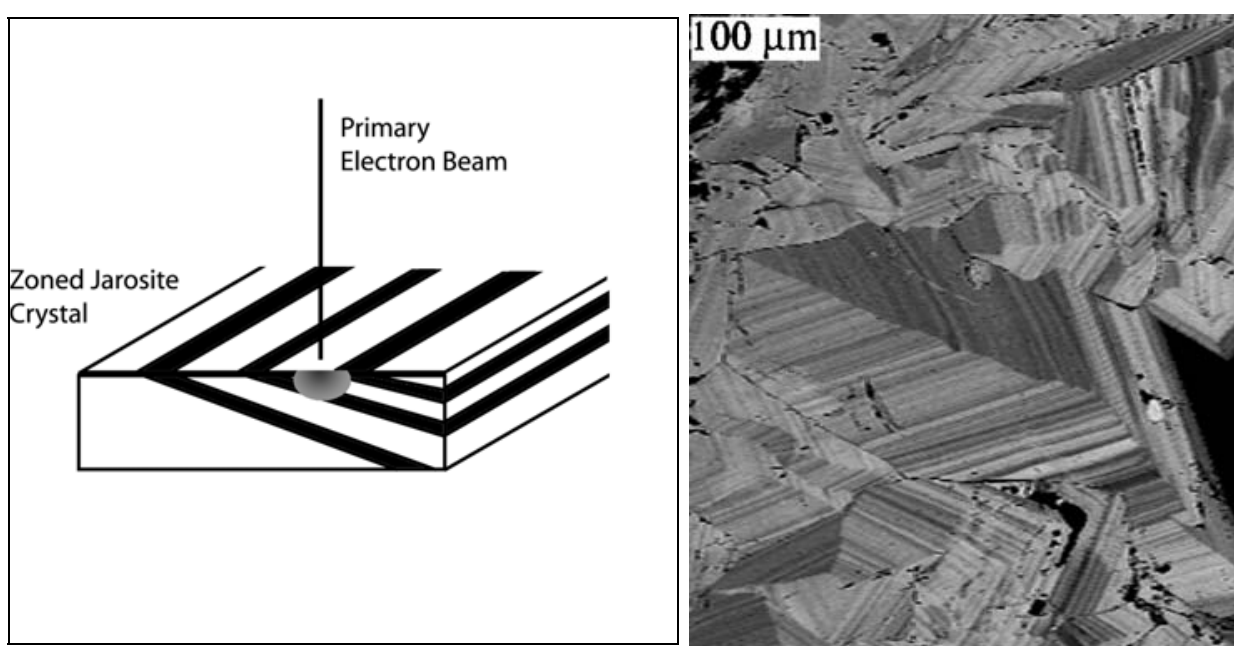

Figure 2. Schematic of zoned jarosite crystal and possible orientation of zoning with depth (left). Backscattered electron image of a complexly zoned jarosite (right). 